Manuela Matos Maturino

(iD) https://orcid.org/0000-0002-9690-1860

Rita de Cássia Pereira Fernandes ${ }^{a}$

iD https://orcid.org/0000-0002-3353-5365

Marco Antônio Vasconcelos Rêgo

(D) https://orcid.org/0000-0001-8206-7353.

a Universidade Federal da Bahia, Faculdade de Medicina da Bahia, Programa de Pós-Graduação em Saúde, Ambiente e Trabalho. Salvador, Bahia, Brasil.

Contato:

Manuela Matos Maturino

E-mail:

manuela.maturino@gmail.com

Artigo baseado na dissertação de Manuela Matos Maturino intitulada A vigilância de ambientes e processos de trabalho na Bahia, defendida em 2015 no curso de Mestrado em Saúde, Ambiente e Trabalho da Universidade Federal da Bahia.

Os autores declaram que o trabalho não foi subvencionado e que não há conflitos de interesses.

Os autores informam que parte deste trabalho foi apresentada no $X$ Congresso Brasileiro de Epidemiologia, na modalidade pôster, em 2017, e no Simpósio Brasileiro de Saúde do Trabalhador, na modalidade oral, em 2017.

Recebido: 19/09/2016

Revisado: 06/04/2017

Aprovado: 20/08/2017

\section{A atuação do SUS na vigilância de ambientes de trabalho: a experiência do Centro Estadual de Referência em Saúde do Trabalhador (Cesat) na Bahia}

\author{
The implementation of work environment surveillance by the \\ Brazilian Unified Health System (SUS): the experience of the \\ State Reference Center for Worker's Health (Cesat) in Bahia
}

\section{Resumo}

Objetivo: descrever e caracterizar as ações de vigilância em ambientes e processos de trabalho desenvolvidas pelo Centro Estadual de Referência em Saúde do Trabalhador (Cesat) e os seus resultados. Métodos: estudo descritivo utilizando documentos técnicos gerados pelas inspeções sanitárias nos ambientes de trabalho desenvolvidas pelo Cesat no estado da Bahia, no período de 2004 a 2013. Resultados: foram analisados 283 relatórios de inspeções realizadas em 211 empresas, de 25 ramos de atividade econômica, na maioria empresas privadas, com maior concentração no ramo das indústrias química e petroquímica. A principal instituição que demandou ações foi o Ministério Público. O mapeamento de riscos e a verificação do cumprimento de recomendações de controle foram os principais motivos das inspeções. Identificou-se um caráter processual das ações, ou seja, contínuo e sistemático, assim como a intersetorialidade, interdisciplinaridade e participação dos trabalhadores. A resolutividade das inspeções foi evidenciada pelo cumprimento total ou parcial das recomendações. Conclusões: o Cesat vem desempenhando papel de estruturação das ações de Vigilância em Saúde do Trabalhador no estado da Bahia. Os achados indicam que sua atuação pode contribuir com o processo de avaliação e consolidação da vigilância em ambientes de trabalho pelo SUS.

Palavras-chave: vigilância em saúde do trabalhador; vigilância do ambiente de trabalho; saúde do trabalhador.

\begin{abstract}
Objective: to describe and characterize the actions and results of the work environments' surveillance actions developed by the Centro Estadual de Referência em Saúde do Trabalhador - Cesat (State Reference Center for Worker's Health). Methods: descriptive study using technical documents generated by the surveillance inspections developed in work environments by the Cesat in the state of Bahia, Brazil, from 2004 to 2013. Results: we analyzed 283 surveillance reports carried out in 211 companies from 25 branches of economic activities, most of them private chemical and petrochemical industries. The Public Prosecutor's Office demanded the majority of the actions. The main reasons for the inspections were mapping risks and verifying compliance with control recommendations. We identified a processual character of the actions, that is, they are continuous and systematic, as well as intersectoral and interdisciplinary approaches, besides workers' participation. The inspections effectiveness was evidenced by the total ou partial compliance with the recommendations. Conclusions: Cesat has been well playing its role of structuring workers' health surveillance actions in the state of Bahia. Our findings indicate that its performance can contribute to the evaluation and consolidation of SUS' (Brazilian Unified Health System) work environment surveillance.
\end{abstract}

Keywords: worker's health surveillance; work environment surveillance; occupational health. 


\section{Introdução}

A Vigilância em Saúde do Trabalhador (Visat) vem sendo construída no Brasil há poucas décadas como prática no âmbito da Saúde pública do Sistema Único de Saúde (SUS). Emergiu de demandas ao setor da Saúde, visando garantir a integralidade da atenção à população trabalhadora, com o desenvolvimento de diferentes ações em vários pontos do país, sob a influência da medicina social latino-americana e da experiência italiana de reforma sanitária. Com os princípios básicos do modelo operário italiano por referência, as ações em saúde do trabalhador foram sendo estruturadas na vigilância em saúde e na assistência no SUS ${ }^{1,2}$.

Daldon e Lancman ${ }^{3}$ relatam que a Visat se organizou com a finalidade de promover a saúde do trabalhador e prevenir os agravos decorrentes das situações de trabalho, tendo o papel não apenas de fiscalizar mas também de educar, sensibilizar e mobilizar os principais atores envolvidos, com a realização de ações conjuntas englobando outros setores.

As bases legais para o desenvolvimento de ações referentes à saúde dos trabalhadores no setor Saúde foram estabelecidas em 1988 com a promulgação da Constituição Federal, a qual criou o SUS. A Constituição possibilitou a ação do setor Saúde nos ambientes de trabalho, tornando-o campo de atuação para o desenvolvimento das ações da Visat.

A Bahia se destacou como um dos estados pioneiros no desenvolvimento de ações em Visat após a criação do Centro de Estudos em Saúde do Trabalhador (Cesat), atualmente denominado Centro Estadual de Referência em Saúde do Trabalhador, vinculado à Superintendência de Vigilância e Proteção da Saúde (Suvisa), da Secretaria da Saúde do Estado da Bahia (Sesab). Esse órgão desenvolve ações de assistência à saúde do trabalhador desde a sua fundação em 1988, atendendo principalmente trabalhadores procedentes da região metropolitana de Salvador (RMS).

As primeiras ações do Cesat foram voltadas para o diagnóstico de doenças ocupacionais e desde então essa instituição tornou-se indispensável para o estabelecimento do nexo causal e a realização de inspeções nos ambientes de trabalho, estruturando a vigilância em ambientes de trabalho no estado ${ }^{4}$. Um passo importante para o fortalecimento das ações de vigilância em ambientes e processos de trabalho no estado da Bahia foi a publicação da Portaria Estadual $\mathrm{n}^{\circ} 2.320$, de 25 de julho de $1995^{5}$, na qual ficaram estabelecidas as atribuições do SUS referentes às ações de Saúde do Trabalhador. Entre essas atribuições, constam as inspeções nos ambientes de trabalho, elaboração de mapas de risco e permissão da participação de representantes dos trabalhadores nas investigações nos ambientes de trabalho. Além dessas, a portaria também disciplina as atribuições do SUS no estado, estabelece a competência dos seus técnicos, as obrigações dos empregadores e até a prerrogativa do uso da força policial, fortalecendo o respaldo legal para o acesso aos ambientes de trabalho ${ }^{6,7}$.

Em nível nacional, um marco importante para a estruturação das ações de Visat foi a publicação da Instrução Normativa da Portaria ${ }^{0} 3.120$, de $1^{\circ}$ de julho de $1998^{8}$, a qual define e orienta as ações da Visat, descrevendo seus objetivos, estratégias e metodologias a serem utilizadas. Posteriormente, em 2012, a Política Nacional de Saúde do Trabalhador e da Trabalhadora (PNSTT) ressalta a importância das ações de Visat para fins de implementação da PNSTT, incluindo ações de vigilância em ambientes e processos de trabalho ${ }^{9}$.

As ações de inspeção nos ambientes de trabalho não são exclusivas do SUS. As ações de fiscalização do Ministério do Trabalho (MT) se caracterizam pelo caráter pontual, com a finalidade de verificar normas e leis, além do caráter punitivo. Diferentemente, o SUS preconiza realizar ações nos ambientes de trabalho orientadas por um caráter processual, educativo, interdisciplinar e intersetorial, com definição de prioridades para as intervenções e a participação dos trabalhadores $^{6,10}$, baseando-se no conhecimento da população trabalhadora e em suas condições de saúde, para que seja possível intervir nos fatores determinantes dos agravos (eliminando, atenuando ou controlando) ${ }^{8,11}$.

Embora ainda sejam predominantes às ações de assistência à saúde do trabalhador no SUS, particularmente com avanços no diagnóstico das doenças ocupacionais nas últimas décadas, as ações de vigilância nos ambientes de trabalho vêm (de forma incipiente no país) se organizando, buscando intervir efetivamente nas condições de trabalho e impactar na redução dos acidentes e doenças do trabalho.

O registro e a sistematização das informações disponíveis no SUS sobre as experiências de vigilância em ambientes de trabalho podem contribuir para avaliação e consolidação dessas ações nos diversos serviços de Saúde do Trabalhador do próprio SUS. Em vista disso, delineou-se este estudo com o objetivo de descrever as ações de vigilância em ambientes de trabalho desenvolvidas pelo Cesat no período de 2004 a 2013, identificando suas principais características e resultados.

\section{Métodos}

Estudo descritivo sobre as ações de vigilância em ambientes e processos de trabalho desenvolvidas pelo Cesat no período de 2004 a 2013. 
Para a coleta dos dados, adotou-se um instrumento construído a partir dos manuais de vigilância em ambientes de trabalho elaborados pelo Cesat. Os dados foram extraídos de 283 documentos técnicos gerados após as inspeções sanitárias, adotados como unidade de observação e análise. Essa fonte foi escolhida admitindo-se que nesses documentos estariam descritos todos os dados colhidos, procedimentos realizados e medidas adotadas pela equipe. A coleta foi realizada no período de 2004 a 2013. O ano de 2013 era o mais recente e disponível para consulta à época do início da coleta, e marcou o último ano da série histórica. O período de uma década foi adotado pela possibilidade deste intervalo permitir identificar as características das ações de vigilância, possíveis tendências e o caráter processual das ações.

O instrumento foi composto por 22 questões, subdividido em três seções referentes aos dados: (a) da empresa, órgão, entidade ou instituição inspecionada; (b) da inspeção realizada no ambiente de trabalho; (c) do desfecho da ação.

Na primeira seção, coletaram-se informações relativas ao tipo de empresa; ramo de atividade econômica; tipos de vínculo empregatício; número de trabalhadores; emprego de menores e tipo de vínculo; tipo de jornada de trabalho.

Na segunda seção, coletaram-se informações relativas à data da inspeção e ao tipo de ação do Cesat, se foi decorrente de curso de projeto de cooperação técnica, ou de projetos especiais por ramo de atividade econômica, ou ação do fluxo contínuo da vigilância; tipo de inspeção: acidente de trabalho (AT) com óbito ou grave, mapeamento de risco, estabelecimento de nexo causal, verificação do cumprimento de recomendações e outros tipos. Nesta variável "tipo de inspeção", optou-se por fazer distinção entre as inspeções para mapeamento de risco e verificação do cumprimento de recomendações, mesmo percebendo a fronteira tênue existente entre elas, uma vez que, para verificar o cumprimento de recomendações, é necessária uma inspeção anterior naquele ambiente de trabalho. No entanto, interessava identificar a ação para verificação de cumprimento como indicador do processo de vigilância. Ainda nessa seção, foram coletadas informações quanto a: município da inspeção; setor inspecionado no local de trabalho, agente solicitante ou origem da demanda da ação de vigilância; participação de trabalhadores na ação; avaliação do risco (qualitativa e/ou quantitativa); participação de outras instituições na ação; formação profissional da equipe técnica da inspeção; data da finalização do relatório.
Na terceira seção, coletaram-se informações relativas ao desfecho da ação de inspeção, se emissão de recomendações, ou encaminhamento do documento para outro órgão. A variável "grau de cumprimento de recomendações" tinha escala de resposta com três itens: cumprida, parcialmente cumprida e não cumprida.

Para a classificação da empresa por ramo de atividade econômica, foi adotada a Classificação Nacional de Atividades Econômicas (CNAE) ${ }^{12}$ especificada no documento técnico, ou para os documentos que não continham essa informação foram utilizados os dados da empresa (nome, natureza da atividade) que constavam no documento, sendo auxiliado por pesquisa em ferramentas de busca para imputar essa classificação.

Foram adotados como critérios de inclusão dos documentos técnicos neste estudo: documentos técnicos de inspeção realizada pela própria equipe de vigilância do Cesat; ter sido gerado após inspeção sanitária; estar disponível em formato eletrônico ou impresso na Coordenação de Vigilância de Ambientes e Processos de Trabalho (Covap/Cesat) durante o período de coleta.

Após o preenchimento do instrumento de coleta, os dados foram processados no programa estatístico Epi Info 6.04 de 1996 (CDC/WHO). Foi realizada a etapa descritiva das variáveis, utilizando frequências absolutas e relativas.

O estudo foi submetido ao Comitê de Ética da Faculdade de Medicina da Bahia, da Universidade Federal da Bahia (CEP-FMB/UFBA), sendo aprovado em 20 de junho de 2014, sob Parecer n ${ }^{\circ}$ 693.113.

\section{Resultados}

Os 283 documentos estudados evidenciaram que o Cesat realizou inspeções em ambientes de trabalho de 211 empresas diferentes no período de 2004 a 2013. Essas inspeções ocorreram em 37 municípios: Salvador, oito outros municípios da RMS e 28 municípios do interior do estado. Considerando todo o período do estudo, houve uma concentração das ações na capital (41,7\%) seguida pela RMS, exceto Salvador $(37,8 \%)$. Nos primeiros cinco anos do estudo (2004-2008), observa-se que 44,9\% das inspeções foram realizadas na RMS, exceto Salvador, mas nos cinco anos seguintes (2009-2013), houve maior proporção das ações de vigilância na capital (54,4\%). O interior do estado foi área de atuação do órgão em todo período, porém com menor número de inspeções $(20,5 \%)$ do que as demais áreas referidas (Tabela 1). 
Tabela 1 Inspeções realizadas pelo Centro Estadual de Referência em Saúde do Trabalhador - Cesat, segundo a localização das empresas e períodos, Bahia, 2004-2013

\begin{tabular}{|c|c|c|c|c|c|c|}
\hline \multirow{3}{*}{ Local } & \multicolumn{6}{|c|}{ Período } \\
\hline & \multicolumn{2}{|c|}{ 2004-2008 } & \multicolumn{2}{|c|}{ 2009-2013 } & \multicolumn{2}{|c|}{ Total } \\
\hline & $n$ & $\%$ & $n$ & $\%$ & $n$ & $\%$ \\
\hline Salvador & 44 & 29,9 & 74 & 54,4 & 118 & 41,7 \\
\hline $\begin{array}{l}\text { Região Metropolitana de Salvador } \\
\text { (exceto Salvador) }\end{array}$ & 66 & 44,9 & 41 & 30,2 & 107 & 37,8 \\
\hline Interior & 37 & 25,2 & 21 & 15,4 & 58 & 20,5 \\
\hline Total & 147 & 100,0 & 136 & 100,0 & 283 & 100,0 \\
\hline
\end{tabular}

\section{Caracterização das empresas inspecionadas}

As inspeções foram realizadas em empresas de 25 ramos de atividade econômica diferentes, sendo $85,5 \%$ empresas privadas; $8,8 \%$ organizações não governamentais e empresas de economia mista e filantrópica e 5,7\% empresas públicas (dados não apresentados em tabela).

Quanto ao ramo de atividade econômica, evidenciou-se maior concentração de indústrias químicas e petroquímicas $(15,5 \%)$, seguidas da indústria de calçados (11\%), construção civil (10,6\%) e comércio de combustíveis a varejo $(9,9 \%)$, e os outros $53 \%$ dos documentos referiram-se a 21 ramos diferentes. A maioria das indústrias inspecionadas localizava-se na RMS, exceto Salvador, composta pelas indústrias químicas e petroquímicas $(79,5 \%)$, de metalurgia e fabricação de peças (66,7\%), de plásticos $(66,7 \%)$ e de fabricação de produtos têxteis (63,6\%). As indústrias de calçados e a maioria (90\%) das empresas do ramo da agricultura, pecuária, produção florestal, pesca e aquicultura eram do interior do estado. As inspeções em supermercados, teleatendimento, educação e serviços foram realizadas na cidade de Salvador (Tabela 2).

As inspeções no setor de Serviços em Educação iniciaram-se em 2008, com maior número de inspeções entre 2009 e 2013; o setor de Serviços (reparação de veículos, marcenaria, serviços complementares) teve inspeções iniciadas entre 2009 e 2013; a última inspeção na indústria têxtil foi realizada em 2008 (dados não apresentados em tabela).

O vínculo empregatício dos trabalhadores estava descrito em 178 documentos (62,9\%). Dentre esses, o trabalho formal (celetista, estatutário, temporário com tempo determinado) representou 94,4\%; os demais foram classificados como sem registro, trabalho informal, autônomo e voluntário. Em quatro documentos $(2,2 \%)$ havia relato de trabalhadores menores de 18 anos. Apenas 149 documentos $(52,6 \%)$ traziam a informação quanto ao número de trabalhadores, variando de 3 a 11.273 trabalhadores (75,3\% com até 336 trabalhadores). O tipo de jornada de trabalho foi relatado em apenas 98 documentos (34,6\%), 70 deles descrevem o trabalho de turno $(71,4 \%)$ (dados não apresentados em tabela).

\section{Caracterização das inspeções realizadas em ambientes de trabalho}

A maioria $(88,3 \%)$ das ações de vigilância em ambientes de trabalho foi parte do fluxo contínuo da vigilância. As ações oriundas de projetos especiais por ramo de atividade econômica ou território (programa de saúde da população carcerária, trabalho agrícola e postos de revenda de combustível) corresponderam a $6,7 \%$, e os projetos de cooperação técnica com outro órgão ou instituição (Superintendência Regional do Trabalho, universidades, órgãos de vigilância e outros órgãos estaduais) representaram 5,0\% das ações (dados não apresentados em tabelas).

O principal demandante de ação de vigilância ao Cesat foi o Ministério Público - MP (56,5\%). A livre demanda do Cesat, incluindo as ações cuja origem não foi especificada no documento técnico, correspondeu a $20,9 \%$ das ações de inspeção, enquanto os projetos especiais representaram 6,7\%. Os outros 15,9\% da demanda atendida distribuíram-se entre demandas originadas em outros órgãos públicos, sindicatos, convênios especiais (ação conjunta do Cesat e Superintendência Regional do Trabalho) e um percentual mínimo de inspeções motivadas por matérias de jornais de grande circulação no estado. As inspeções demandadas por convênios especiais aconteceram exclusivamente em Salvador, assim como as motivadas por notícias em jornais. O MP demandou maior número de inspeções na RMS, exceto Salvador $(44,4 \%)$. A demanda de projetos especiais ocorreu na sua grande maioria em Salvador (78,9\%) (Tabela 3).

A participação de outras instituições (além do demandante) nas ações de vigilância ocorreu em $75,6 \%$ das ações documentadas. Essa participação se deu na origem da demanda $(85,5 \%)$, durante a própria inspeção $(6,1 \%)$, ou em ambas $(8,4 \%)$ (dados não apresentados em tabela). 
Tabela 2 Ramos de atividade das empresas inspecionadas pelo Centro Estadual de Referência em Saúde do Trabalhador - Cesat, segundo a localização geográfica, Bahia, 2004-2013

\begin{tabular}{|c|c|c|c|c|c|c|c|c|}
\hline \multirow[t]{2}{*}{ Ramo de atividade } & \multicolumn{2}{|c|}{ Salvador } & \multicolumn{2}{|c|}{$\begin{array}{c}\text { Região Metropolitana } \\
\text { de Salvador } \\
\text { (Exceto Salvador) }\end{array}$} & \multicolumn{2}{|c|}{ Interior } & \multicolumn{2}{|c|}{ Total } \\
\hline & $n$ & $\% *$ & $n$ & $\%$ ** & $n$ & $\%$ * & $n$ & $\%$ 档 \\
\hline Indústria química e petroquímica & 8 & 18,2 & 35 & 79,5 & 1 & 2,3 & 44 & 15,5 \\
\hline Indústria de calçados & - & - & - & - & 31 & 100,0 & 31 & 11,1 \\
\hline Construção civil & 18 & 60,0 & 10 & 33,3 & 2 & 6,7 & 30 & 10,6 \\
\hline Comércio de combustíveis a varejo & 13 & 46,4 & 15 & 53,6 & - & - & 28 & 9,9 \\
\hline Mineração (extração e beneficiamento) & - & - & 11 & 57,9 & 8 & 42,1 & 19 & 6,7 \\
\hline Educação & 16 & 100,0 & - & - & - & - & 16 & 5,7 \\
\hline Teleatendimento & 15 & 100,0 & - & - & - & - & 15 & 5,3 \\
\hline Metalurgia e fabricação de peças & 4 & 33,3 & 8 & 66,7 & - & - & 12 & 4,2 \\
\hline Fabricação de produtos têxteis & 2 & 18,2 & 7 & 63,6 & 2 & 18,2 & 11 & 3,9 \\
\hline $\begin{array}{l}\text { Agricultura, pecuária, produção florestal, } \\
\text { pesca e aquicultura }\end{array}$ & 1 & 10,0 & - & - & 9 & 90,0 & 10 & 3,5 \\
\hline Transporte & 5 & 55,6 & 4 & 44,4 & - & - & 9 & 3,2 \\
\hline $\begin{array}{l}\text { Manutenção, reparação e instalação de } \\
\text { máquinas e equipamentos }\end{array}$ & 3 & 37,5 & 3 & 37,5 & 2 & 25,0 & 8 & 2,8 \\
\hline Supermercado & 8 & 100,0 & - & - & - & - & 8 & 2,8 \\
\hline Hospitais e unidades de saúde & 8 & 100,0 & - & - & - & - & 8 & 2,8 \\
\hline $\begin{array}{l}\text { Administração pública, defesa e seguridade } \\
\text { social }\end{array}$ & 5 & 71,4 & - & - & 2 & 28,6 & 7 & 2,5 \\
\hline Indústria de plásticos & 2 & 33,3 & 4 & 66,7 & - & - & 6 & 2,1 \\
\hline Locação de mão de obra temporária & 3 & 60,0 & 2 & 40,0 & - & - & 5 & 1,8 \\
\hline Fabricação de produtos alimentícios & - & - & 2 & 66,7 & 1 & 33,3 & 3 & 1,1 \\
\hline Comércio de gás & 2 & 66,7 & 1 & 33,3 & - & - & 3 & 1,1 \\
\hline Outros (fibra de vidro e colchões) & 1 & 33,3 & 2 & 66,7 & - & - & 3 & 1,1 \\
\hline Reciclagem & - & - & 2 & 100,0 & - & - & 2 & 0,7 \\
\hline Serviços complementares & 1 & 50,0 & 1 & 50,0 & - & - & 2 & 0,7 \\
\hline Outras atividades de serviços & 1 & 100,0 & - & - & - & - & 1 & 0,4 \\
\hline Reparação de veículos & 1 & 100,0 & - & - & - & - & 1 & 0,4 \\
\hline Marcenaria & 1 & 100,0 & - & - & - & - & 1 & 0,4 \\
\hline Total & 118 & 41,7 & 107 & 37,8 & 58 & 20,5 & 283 & 100,0 \\
\hline
\end{tabular}

Com relação ao motivo das inspeções, observou-se que, no total do período, a realização de mapeamento de riscos e a verificação do cumprimento de recomendações de controle foram os principais motivos de ida do Cesat aos ambientes de trabalho, totalizando $74,2 \%$ das inspeções, com igual representatividade (37,1\% cada). As inspeções para realizar mapeamento de riscos, verificar o cumprimento de recomendações e investigar o acidente de trabalho com óbito ocorreram em todo o período estudado. As inspeções de verificação do cumprimento de recomendações representaram mais de $50 \%$ das ações documentadas em 2006 (52,0\%) e 2013 (53,8\%). O mapeamento de riscos representou $56,7 \%$ dos documentos emitidos em 2008. O único documento para licenciamento ambiental foi emitido em 2007 (Tabela 4).

O Cesat realizou inspeções para verificar o cumprimento de recomendações e mapeamento de risco em praticamente todos os ramos de atividade econômica As ações para mapeamento de risco foram mais representativas no ramo do comércio de combustível a varejo $(20,0 \%)$, enquanto para verificar o cumprimento de recomendações, destacaram-se os ramos 
Tabela 3 Inspeções realizadas pelo Centro Estadual de Referência em Saúde do Trabalhador - Cesat, segundo a origem da demanda e localização geográfica, Bahia, 2004-2013

\begin{tabular}{|c|c|c|c|c|c|c|c|c|}
\hline \multirow{3}{*}{ Origem da demanda } & \multicolumn{8}{|c|}{ Localização } \\
\hline & \multicolumn{2}{|c|}{ Salvador } & \multicolumn{2}{|c|}{$\begin{array}{l}\text { Região Metropolitana de } \\
\text { Salvador (exceto Salvador) }\end{array}$} & \multicolumn{2}{|c|}{ Interior } & \multicolumn{2}{|c|}{ Total } \\
\hline & $n$ & $\% *$ & $n$ & $\% *$ & $n$ & $\%$ * & $n$ & 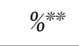 \\
\hline Ministério Público & 52 & 32,5 & 71 & 44,4 & 37 & 23,1 & 160 & 56,5 \\
\hline Livre demanda & 26 & 44,0 & 23 & 39,0 & 10 & 17,0 & 59 & 20,9 \\
\hline Projetos especiais & 15 & 78,9 & 1 & 5,3 & 3 & 15,8 & 19 & 6,7 \\
\hline Outros órgãos públicos & 6 & 33,3 & 7 & 38,9 & 5 & 27,8 & 18 & 6,4 \\
\hline Sindicatos & 4 & 33,3 & 5 & 41,7 & 3 & 25,0 & 12 & 4,2 \\
\hline Convênios especiais & 12 & 100,0 & - & & - & & 12 & 4,2 \\
\hline Notícias em jornais & 3 & 100,0 & - & & - & & 3 & 1,1 \\
\hline Total & 118 & 41,7 & 107 & 37,8 & 58 & 20,5 & 283 & 100,0 \\
\hline
\end{tabular}

* Porcentagem em relação à coluna Total

* * Porcentagem em relação à linha Total

Tabela 4 Inspeções realizadas pelo Centro Estadual de Referência em Saúde do Trabalhador - Cesat, segundo o motivo e ano de emissão do documento técnico, Bahia, 2004-2013

\begin{tabular}{|c|c|c|c|c|c|c|c|c|c|c|c|c|c|c|}
\hline \multicolumn{15}{|c|}{ Motivo } \\
\hline & \multicolumn{2}{|c|}{$\begin{array}{l}\text { Verificação de } \\
\text { recomendações }\end{array}$} & \multicolumn{2}{|c|}{$\begin{array}{l}\text { Mapeamento dos } \\
\text { fatores de riscos }\end{array}$} & \multicolumn{2}{|c|}{$\begin{array}{c}\text { Acidente de trabalho } \\
\text { com óbito }\end{array}$} & \multicolumn{2}{|c|}{$\begin{array}{l}\text { Acidente de } \\
\text { trabalho grave }\end{array}$} & \multicolumn{2}{|c|}{$\begin{array}{c}\text { Estabelecimento } \\
\text { de nexo causal }\end{array}$} & \multicolumn{2}{|c|}{$\begin{array}{c}\text { Licenciamento } \\
\text { ambiental }\end{array}$} & \multicolumn{2}{|c|}{ Total } \\
\hline & $n$ & $\%$ \% & $n$ & \%* & $n$ & $\%$ * & $n$ & \%米 & $n$ & $\%$ * & $n$ & $\% *$ & $n$ & $\% * *$ \\
\hline 2004 & 14 & 43,8 & 8 & 25,0 & 7 & 21,9 & 1 & 3,1 & 2 & 6,3 & - & - & 32 & 11,3 \\
\hline 2005 & 10 & 40,0 & 4 & 16,0 & 6 & 24,0 & - & - & 5 & 20,0 & - & - & 25 & 8,8 \\
\hline 2006 & 13 & 52,0 & 6 & 24,0 & 1 & 4,0 & 1 & 4,0 & 4 & 16,0 & - & - & 25 & 8,8 \\
\hline 2007 & 5 & 14,3 & 17 & 48,6 & 5 & 14,3 & 6 & 17,1 & 1 & 2,9 & 1 & 2,9 & 35 & 12,4 \\
\hline 2008 & 8 & 26,7 & 17 & 56,7 & 4 & 13,3 & 1 & 3,3 & - & - & - & - & 30 & 10,6 \\
\hline 2009 & 13 & 38,2 & 12 & 35,3 & 4 & 11,8 & 3 & 8,8 & 2 & 5,9 & - & - & 34 & 12,0 \\
\hline 2010 & 6 & 33,3 & 8 & 44,4 & 4 & 22,2 & - & - & - & - & - & - & 18 & 6,4 \\
\hline 2011 & 13 & 44,8 & 11 & 7,9 & 4 & 13,8 & - & - & 1 & 3,4 & - & - & 29 & 10,2 \\
\hline 2012 & 9 & 31,0 & 14 & 48,3 & 3 & 10,3 & 3 & 10,3 & - & - & - & - & 29 & 10,2 \\
\hline 2013 & 14 & 53,8 & 8 & 30,8 & 3 & 11,5 & 1 & 3,8 & & - & & - & 26 & 9,2 \\
\hline Total & 105 & 37,1 & 105 & 37,1 & 41 & 14,5 & 16 & 5,7 & 15 & 5,3 & 1 & 0,3 & 283 & 100,0 \\
\hline
\end{tabular}

* Porcentagem em relação à coluna Total

* * Porcentagem em relação à linha Total

da indústria química e petroquímica e indústrias de calçados (21,9\% cada). Evidencia-se como maior demandante das inspeções para checar a execução das recomendações, o MP $(93,2 \%)$ (dado não apresentado em tabela). Os AT com óbito foram investigados na sua maioria no ramo da construção civil $(31,7 \%)$ (Tabela 5). Nos locais de trabalho, os principais setores inspecionados foram: de produção - área operacional de desenvolvimento de produtos e serviços $(68,5 \%)$, área total da empresa $(19,4 \%)$, área operacional de treinamento $(4,9 \%)$ e as demais áreas - serviço médico da empresa, área de apoio, área rural, área de entorno ambiental, área administrativa da empresa, espaço de rua $(7,2 \%)$ (dados não apresentados em tabela).

Em todos os 283 documentos, foi relatada a participação de trabalhadores e/ou prepostos das instituições como informantes durante as inspeções. Identificou-se em $71 \%$ dos documentos relato do encaminhamento de documentos pela empresa para análise do Cesat, relativos a informações dos trabalhadores ou da própria empresa (dados não apresentados em tabela). 
Tabela 5 Inspeções realizadas pelo Centro Estadual de Referência em Saúde do Trabalhador - Cesat, segundo motivo e ramo de atividade econômica, Bahia, 2004-2013

\begin{tabular}{|c|c|c|c|c|c|c|c|c|c|c|c|c|c|c|}
\hline \multirow{3}{*}{ Ramo de atividade } & \multicolumn{14}{|c|}{ Motivo da inspeção } \\
\hline & \multicolumn{2}{|c|}{$\begin{array}{l}\text { Verificação de } \\
\text { recomendações }\end{array}$} & \multicolumn{2}{|c|}{$\begin{array}{l}\text { Mapeamento } \\
\text { dos fatores de } \\
\text { riscos }\end{array}$} & \multicolumn{2}{|c|}{$\begin{array}{l}\text { Acidente de } \\
\text { trabalho com } \\
\text { óbito }\end{array}$} & \multicolumn{2}{|c|}{$\begin{array}{l}\text { Acidente de } \\
\text { trabalho grave }\end{array}$} & \multicolumn{2}{|c|}{$\begin{array}{c}\text { Estabelecimento } \\
\text { de nexo causal }\end{array}$} & \multicolumn{2}{|c|}{$\begin{array}{c}\text { Licenciamento } \\
\text { ambiental }\end{array}$} & \multicolumn{2}{|c|}{ Total } \\
\hline & $n$ & $\%$ & $n$ & $\%$ & $n$ & $\%$ & $n$ & $\%$ & $n$ & $\%$ & $n$ & $\%$ & $n$ & $\%$ \\
\hline $\begin{array}{l}\text { Indústria química e } \\
\text { petroquímica }\end{array}$ & 23 & 21,9 & 10 & 9,5 & 6 & 14,6 & 2 & 12,5 & 2 & 13,3 & 1 & 100,0 & 44 & 15,5 \\
\hline Indústria de calçados & 23 & 21,9 & 6 & 5,7 & - & - & 2 & 12,5 & - & - & - & - & 31 & 11,1 \\
\hline Construção civil & 8 & 7,6 & 4 & 3,8 & 13 & 31,7 & 3 & 18,8 & 2 & 13,3 & - & - & 30 & 10,6 \\
\hline $\begin{array}{l}\text { Comércio de } \\
\text { combustíveis a varejo }\end{array}$ & 6 & 5,7 & 21 & 20,0 & 1 & 2,4 & - & - & - & - & - & - & 28 & 9,9 \\
\hline $\begin{array}{l}\text { Mineração (extração e } \\
\text { beneficiamento) }\end{array}$ & 7 & 6,7 & 5 & 4,8 & 3 & 7,3 & 2 & 12,5 & 2 & 13,3 & - & - & 19 & 6,7 \\
\hline Educação & 3 & 2,9 & 13 & 12,4 & - & - & - & - & - & - & - & - & 16 & 5,7 \\
\hline Teleatendimento & 7 & 6,7 & 8 & 7,6 & - & - & - & - & - & - & - & - & 15 & 5,3 \\
\hline $\begin{array}{l}\text { Metalurgia e } \\
\text { fabricação de peças }\end{array}$ & 7 & 6,7 & 2 & 1,9 & 1 & 2,4 & 2 & 12,5 & - & - & - & & 12 & 4,2 \\
\hline $\begin{array}{l}\text { Fabricação de } \\
\text { produtos têxteis }\end{array}$ & 6 & 5,7 & 2 & 1,9 & - & - & - & - & 3 & 20,0 & - & - & 11 & 3,9 \\
\hline $\begin{array}{l}\text { Agricultura, pecuária, } \\
\text { produção florestal, } \\
\text { pesca e aquicultura }\end{array}$ & 1 & 1,0 & 6 & 5,7 & - & - & - & - & 3 & 20,0 & - & - & 10 & 3,5 \\
\hline Transporte & 1 & 1,0 & 2 & 1,9 & 4 & 9,8 & 1 & 6,3 & 1 & 6,7 & - & - & 9 & 3,2 \\
\hline $\begin{array}{l}\text { Manutenção, } \\
\text { reparação e instalação } \\
\text { de máquinas e } \\
\text { equipamentos }\end{array}$ & 1 & 1,0 & 1 & 1,0 & 5 & 12,2 & - & - & 1 & 6,7 & - & - & 8 & 2,8 \\
\hline Supermercado & 2 & 1,9 & 5 & 4,8 & 1 & 2,4 & - & - & - & - & - & - & 8 & 2,8 \\
\hline $\begin{array}{l}\text { Hospitais e unidades } \\
\text { de saúde }\end{array}$ & 2 & 1,9 & 5 & 4,8 & - & - & - & - & 1 & 6,7 & - & - & 8 & 2,8 \\
\hline $\begin{array}{l}\text { Administração } \\
\text { pública, defesa e } \\
\text { seguridade social }\end{array}$ & 2 & 1,9 & 5 & 4,8 & - & - & - & - & - & - & - & - & 7 & 2,5 \\
\hline Indústria de plásticos & 1 & 1,0 & 3 & 2,9 & - & - & 2 & 12,5 & - & - & - & - & 6 & 2,1 \\
\hline $\begin{array}{l}\text { Locação de mão de } \\
\text { obra temporária }\end{array}$ & 1 & 1,0 & - & - & 3 & 7,3 & 1 & 6,3 & - & - & - & - & 5 & 1,8 \\
\hline $\begin{array}{l}\text { Fabricação de } \\
\text { produtos alimentícios }\end{array}$ & 2 & 1,9 & - & - & 1 & 2,4 & - & - & - & - & - & - & 3 & 1,1 \\
\hline Comércio de gás & 1 & 1,0 & 2 & 1,9 & - & - & - & - & - & - & - & - & 3 & 1,1 \\
\hline $\begin{array}{l}\text { Outros (fibra de vidro } \\
\text { e colchões) }\end{array}$ & 1 & 1,0 & 1 & 1,0 & 1 & 2,4 & - & - & - & - & - & - & 3 & 1,1 \\
\hline Reciclagem & - & - & 1 & 1,0 & - & - & 1 & 6,3 & & - & - & - & 2 & 0,7 \\
\hline $\begin{array}{l}\text { Serviços } \\
\text { complementares }\end{array}$ & - & - & - & - & 2 & 4,9 & - & - & - & - & - & - & 2 & 0,7 \\
\hline $\begin{array}{l}\text { Outras atividades de } \\
\text { serviços }\end{array}$ & - & - & - & - & 1 & 2,4 & - & - & - & - & - & - & 1 & 0,4 \\
\hline Reparação de veículos & - & - & - & - & 1 & 2,4 & - & & & - & - & & 1 & 0,4 \\
\hline Marcenaria & - & - & - & - & 1 & 2,4 & - & - & - & - & - & - & 1 & 0,4 \\
\hline Total & 105 & 37,1 & 105 & 37,1 & 41 & 14,5 & 16 & 5,7 & 15 & 5,3 & 1 & 0,3 & 283 & 100,0 \\
\hline
\end{tabular}


A avaliação qualitativa do risco foi realizada em todas as inspeções, sendo que em 59 dos documentos técnicos $(20,8 \%)$ referencia-se a associação da análise quantitativa e quantitativa de risco (avaliação pontual do ruído com 59,3\%, avaliação da iluminação com $13,6 \%$, e avaliação de ambas com $27,1 \%$, dados não apresentados em tabela).

As inspeções foram realizadas na sua quase totalidade (94\%) por mais de dois técnicos na equipe de inspeção, e em apenas $6 \%$ dos documentos relata-se a presença de um técnico. Observou-se a diversidade na formação dos profissionais que compõem a equipe técnica, estando presente nas inspeções, no mínimo, um engenheiro químico (49,7\%); um médico (45,9\%) e um biólogo (34,6\%). A distribuição dos documentos, segundo o ano de emissão, manteve-se regular em todo o período do estudo. Observou-se que, em média, os documentos foram finalizados em 122 dias (mediana de 90 dias), sendo que $24,8 \%$ dos relatórios levaram menos de 45 dias para serem finalizados (dados não apresentados em tabela).

\section{Caracterização do desfecho da ação}

Dos 283 documentos, 72,7\% emitiram algum tipo de proposta ou recomendação para a empresa, associada ou não a outro desfecho. As recomendações foram referentes às adequações das situações que podem afetar a saúde dos trabalhadores e da população em geral, com base na legislação vigente e no conhecimento disponível na literatura técnica/científica, além das boas práticas reconhecidas.

Quando as recomendações eram para adoção imediata, antes mesmo da finalização do documento técnico, emitia-se uma notificação com prazos para o cumprimento das propostas. Nos documentos elaborados após a realização de uma inspeção para monitoramento (ação processual ou de análise de recomendações), havia o registro do grau de cumprimento das recomendações efetuadas anteriormente, podendo estar ou não associadas a novas recomendações.

Nos documentos que tiveram em seu desfecho a análise do cumprimento de recomendações $(34,6 \%)$, em $45,7 \%$ deles referenciavam que a maioria das recomendações analisadas foi atendida, $26,7 \%$ referiram que a maioria das recomendações analisadas não foi atendida e $21,9 \%$, que a maioria das recomendações analisadas foi parcialmente atendida. Em apenas 5,7\% das inspeções não foi possível reavaliar o local de trabalho, não sendo, portanto, possível emitir o grau do cumprimento das recomendações.

Em 24,0\% dos documentos há referência sobre a realização de algum tipo de encaminhamento deste documento, sendo o destinatário por vezes registrado, principalmente em documentos referentes a AT grave e com óbito (encaminhados para o trabalhador vitimado ou sua família, empresa, sindicato da categoria e por vezes ao MP e ao INSS). Todos os documentos estavam assinados pelos técnicos que realizaram a inspeção.

\section{Discussão}

Nos anos iniciais do período estudado (20042008), quase metade das ações de inspeções em ambientes de trabalho desenvolvidas pelo Cesat aconteceram na RMS, exceto Salvador, onde concentram-se as grandes indústrias, integrantes principalmente do Complexo Petroquímico de Camaçari e do Centro Industrial de Aratu. Essa região sempre foi área de atuação do Cesat, sendo o local de desenvolvimento dos primeiros projetos especiais de Visat no estado 4 .

Posteriormente, a capital do estado, Salvador, passou a ser o maior campo de atuação do Cesat, o que provavelmente está associado ao aumento proporcional de ações no setor de Serviços, com concentração das inspeções a partir de 2009, embora mantidas as inspeções nas indústrias e atividades na RMS. A redução do número de ações realizadas no interior do estado entre 2009 e 2013 pode se explicar pelo que foi descrito por Nobre ${ }^{13}$, referindo-se ao momento vivenciado pelo Cesat a partir de 2007. A autora refere que com o "fortalecimento das estratégias de descentralização" por parte do governo estadual à época e a "atuação compartilhada com os municípios, visando o fortalecimento e ampliação da Rede de Atenção à Saúde do Trabalhador”, foi favorecido o processo de descentralização das ações de Visat para os municípios. Desde esse período, o Cesat vem realizando capacitações para as equipes dos Centros de Referência em Saúde do Trabalhador (Cerest), Diretorias Regionais de Saúde (Dires) e Visat municipais, além de desempenhar apoio técnico para a realização das ações de vigilância em ambientes de trabalho.

Evidenciou-se que diversas foram as demandas atendidas pelo Cesat para inspeção em ambientes de trabalho. A participação do MP como principal demandante dessas ações foi evidenciada (mais de $50 \%$ das ações documentadas no período). É importante considerar que o MP atua em resposta a denúncias dos trabalhadores e suas organizações. $\mathrm{O}$ estudo revelou que essa parceria entre o SUS e o MP foi determinante para o caráter processual das ações, haja vista que quase todas as ações de verificação de recomendações foram demandadas pelo MP. Isso evidencia que a necessidade de "promover o ajustamento de condutas" pelas empresas, como 
parte da missão do MP, imputou à ação do Cesat este caráter processual, tão almejado pelo modelo de Visat no SUS.

Há registros na literatura da existência da articulação do Cesat com o MP desde metade dos anos 1990, como ação interinstitucional em atuações voltadas às empresas do ramo industrial na $\mathrm{RMS}^{4}$. Nobre et al. ${ }^{14}$ descrevem a parceria entre o MP e o Cesat como exemplo de ação intersetorial, a qual possibilitou a realização de diversas audiências para discussão e negociação de melhorias das condições de trabalho, envolvendo empresas, sindicatos e outros órgãos públicos, e utilizando como base para a negociação os documentos técnicos do Cesat.

Cardoso $^{15}$ relata a percepção dos técnicos do Cerest estadual do Amazonas em relação a parcerias com outros setores, sendo que o MP foi o mais referido nas experiências de Visat naquele estado. No estudo de Machado et al. ${ }^{16}$, a demanda atendida pelos Cerest no âmbito nacional provém dos sindicatos $(38,8 \%)$, seguidos pelo MP $(34,4 \%)$ e por serviços sentinela $(34,0 \%)$, sendo diferente da realidade encontrada no Cesat, em que a demanda dos sindicatos no período estudado foi bem inferior à do MP.

Na maioria dos documentos, há referência de outra instituição e/ou setor no desenvolvimento da ação, em especial, na origem da demanda. No entanto, a participação de outras instituições ou setores na inspeção foi mínima (incluindo Cerest, Vigilância Sanitária Estadual, Vigilância Epidemiológica Estadual, Diretorias Regionais de Saúde), mas isso pode apenas refletir o caráter técnico e especializado da inspeção do Cesat.

Nas orientações técnicas para ações de vigilância de ambientes e processos de trabalho ${ }^{17}$, há referência da integração da Visat com outros setores da Vigilância em Saúde (Vigilância Sanitária, Epidemiológica e Ambiental), além de setores como Meio Ambiente, Agricultura, MP, MT, dentre outros. Nota-se dificuldade em desenvolver essas ações interinstitucionais, o que é revelado pelos resultados apresentados que evidenciam a efetividade apenas da parceria com o $\mathrm{MP}^{6}$.

O Cesat realizou prioritariamente ações para mapeamento de risco e verificação de recomendações de medidas de controle de risco. Fernandes e Rêgo ${ }^{4}$ referem que nos anos iniciais do Cesat a maioria das ações em ambientes de trabalho (98\%) era para subsidiar o estabelecimento do nexo causal das doenças com o trabalho. Já no final da década de 1990 é notória a mudança do motivo das inspeções, sendo o mapeamento de risco responsável por mais da metade das inspeções realizadas (56\%). Essa tendência da redução proporcional de inspeções para o diagnóstico individual da doença ocupacional, com aumento de inspeções de mapeamento de risco, se manteve no período deste estudo. A consolidação das ações nos ambientes de trabalho, com o acúmulo técnico e político do Cesat, conduziu a uma mudança de prioridade, evidenciada nessas ações que ultrapassam o papel subsidiário à clínica ocupacional, caraterística das ações iniciais do órgão. É possível também afirmar que este processo de redirecionamento da natureza das ações foi se consolidando e se fortalecendo à medida que aumentavam as demandas do MP. No entanto, o MP não teria se constituído em um demandante, caso o Cesat não tivesse inaugurado esta nova perspectiva, inclusive tornando visível este tipo de ação que o MP passaria a demandar.

Boa parte do que é verificação de recomendações decorre de mapeamento de risco prévio. A classificação adotada quanto à verificação de recomendações tem limites, mas pretende dar visibilidade ao que se adota no registro documental. Ademais, evidencia-se o caráter processual da ação, sendo o ambiente de trabalho objeto de atenção ao longo de um período, que começa com a primeira inspeção e segue no acompanhamento de intervenções, ou seja, na verificação das recomendações feitas anteriormente pelo Cesat.

Essas inspeções podem, além disso, verificar recomendações que constam em Termos de Ajustamentos de Conduta (TAC), em inquéritos civis públicos ou em processos judiciais. Esse acompanhamento contínuo e sistemático está previsto no modelo de vigilância preconizado pelo SUS, diferente das ações do MT nas quais predominam ações pontuais, de caráter fiscalizador, unidisciplinares e definidoras de sanções ${ }^{6,10,14,17,18}$.

Dentre os documentos referentes ao acompanhamento de ações através da verificação do cumprimento de recomendações, nota-se que a maioria das empresas cumpriu total ou parcialmente com as recomendações estabelecidas, o que reforça a importância da parceria do Cesat com o MP, uma vez que a maioria dessas ações de avaliação de recomendações foi demanda desse órgão (93,6\%). O poder da ação que envolve o MP deve estar refletido nesse resultado.

Machado et al. ${ }^{16}$ relatam que nos Cerest a demanda que sobressai motivando as inspeções é o estabelecimento de nexo causal. Nos dados encontrados neste estudo, essa motivação correspondeu apenas a $5,3 \%$ das inspeções desenvolvidas pelo Cesat, com concentração no período de 2004 a 2008, demonstrando uma demanda decrescente desse tipo de inspeção e a priorização de ações de cunho e interesse coletivos. 
É possível que os serviços municipais de Visat, incluídos na descrição de Machado et al. ${ }^{16}$, mais recentes na rede de saúde, tenham nas ações para subsidiar o nexo causal a principal motivação de inspeções nos ambientes de trabalho, como uma fase ainda inaugural das ações nos ambientes de trabalho, conforme assinalado acima a propósito da trajetória do Cesat.

A notícia em jornais de grande circulação no estado foi uma das fontes de informação sobre AT citadas nos documentos técnicos que motivaram algumas inspeções, constituindo-se como uma fonte de dados e informações complementares aos bancos de dados oficiais, além de ser um meio de informação de baixo custo, fácil acesso e que inclui informações sobre AT com trabalhadores informais e funcionários públicos ${ }^{19,20}$. No entanto, essas notícias não geraram, no período estudado, grande número de inspeções, uma vez que os acidentes noticiados são, em sua maioria, acidentes de trânsito, acidente de trajeto ou resultados de violência intencional, e esses tipos de acidente de trabalho não são objeto de investigação do Cesat, pois que, segundo Jacobina et al. ${ }^{21}$, "têm determinação de outra ordem e demandam estratégias de prevenção e articulação com outros atores sociais e instituições", não havendo como intervir exclusivamente nos ambientes de trabalho a fim de proteger a vida e saúde dos trabalhadores vitimados por estes.

As inspeções decorrentes de AT são importantes para compreensão das circunstâncias em que aconteceram os acidentes, além de possibilitarem intervenções para prevenção de novos acidentes na empresa inspecionada, superando a ação restrita sobre um evento isolado, mas promovendo melhorias para a coletividade. Para Vilela, Almeida e Mendes ${ }^{22}$, "esses acidentes são influenciados por aspectos da situação imediata de trabalho" estando, portanto, o ambiente e o processo de trabalho relacionados diretamente ao acontecimento. Os acidentes graves ou com óbito são investigados pelo Cesat desde 1996, e os documentos técnicos gerados pela investigação desses acidentes vêm sendo utilizados para orientar ações judiciais, previdenciárias e regressivas, algumas já concluídas com êxito ${ }^{14}$.

Em muitos dos documentos existe o relato de mais de uma inspeção realizada pela equipe de Visat para conclusão desse documento. Não foi possível o registro quantitativo destas inspeções, haja vista que a unidade de observação foi o documento técnico no período estudado e não a inspeção.

Quanto ao ambiente de trabalho inspecionado, o setor ou área de produção foi o principal setor. Esse dado revela a ação do órgão na área operacional das empresas, onde potencialmente existem os riscos tradicionalmente identificados, como ruído, riscos de acidente, riscos químicos, dentre outros.

A participação dos trabalhadores nas ações de Visat foi evidenciada neste estudo. A Política Nacional de Saúde do Trabalhador e da Trabalhadora, em seu artigo $6^{\circ}$, explicita a importância de ouvir os trabalhadores, pois são eles que lidam no dia a dia com o ambiente e os processos de trabalho ${ }^{9}$. Ao apresentar que em todas as ações que geraram documento técnico houve a participação do trabalhador como informante, é revelada a prática do Cesat em ouvir o trabalhador durante a inspeção, embora a participação dos trabalhadores no planejamento das ações ou nas inspeções não tenha sido verificada como prática habitual. Apesar desse limite de participação, é importante ressaltar o registro da percepção dos trabalhadores acerca das condições de trabalho como uma característica constitutiva do modo de ação do Cesat.

Essa participação pode ocorrer em todas as etapas da ação de vigilância em ambientes de trabalho ${ }^{6,14}$, admitindo-se que o trabalhador seja capaz de informar as "sutis diferenças existentes entre o trabalho prescrito e o trabalho real que explicam os agravos e o que deve ser modificado para a obtenção dos resultados desejados"17. Em consonância, a Fundação Europeia para a Melhoria das Condições de Vida e de Trabalho realiza pesquisas (através de questionários) com trabalhadores a fim de fornecer, através dos seus Inquéritos, um panorama das condições de trabalho na Europa, contribuindo para o desenvolvimento de políticas, especialmente sobre a qualidade do trabalho e questões de emprego ${ }^{23}$.

Cardoso $^{15}$ cita a dificuldade de inserção dos trabalhadores enquanto integrantes da equipe de inspeção no estado do Amazonas, relatando a participação destes como informantes na inspeção. Reconhece a participação dos trabalhadores nas ações de Visat como "membro do conjunto de sujeitos que têm responsabilidades com o desenvolvimento das ações de Visat”.

Durante a inspeção em ambientes de trabalho, riscos à saúde do trabalhador foram identificados, avaliados e registrados. Existem várias técnicas que possibilitam a análise dos riscos. O Cesat realizou prioritariamente avaliações ambientais qualitativas, algumas poucas vezes complementadas por avaliações ambientais quantitativas. Kauppinen e Toikkanen ${ }^{24}$ descrevem o desenvolvimento de ações de vigilância dos riscos combinando o julgamento profissional e as medições disponíveis, vistorias e outros dados, favorecendo a definição das prioridades, de forma racional, com consequente ação de prevenção eficaz. 
A avaliação ambiental qualitativa baseia-se no reconhecimento do risco, determinação e localização das possíveis fontes geradoras, meio de propagação, tipo de exposição, número de trabalhadores expostos, possíveis danos causados à saúde dos trabalhadores e medidas de controle que podem ser adotadas. Essas informações devem ser caracterizadas por setor ou posto de trabalho e correlacionadas com os dados existentes na empresa, indicativos de comprometimento da saúde dos trabalhadores, com base no julgamento profissional ${ }^{25}$.

As referências em Visat recomendam que as ações sejam realizadas por mais de um técnico capacitado $^{17,18}$, sendo evidenciado essa prática nas inspeções do Cesat, possibilitando a incorporação de diferentes saberes e possibilitando a sua integração. $\mathrm{O}$ trabalho em equipe multiprofissional e interdisciplinar identificado neste estudo com os dados empíricos do Cesat é descrito por Nobre et al. ${ }^{14}$ ao relatarem que a inspeção em ambientes de trabalho é antes de tudo, "um desafio e um trabalho em equipe, coletivo; de uma equipe multiprofissional que enfrenta o desafio do exercício da inter e da transdiciplinaridade".

A diversidade de empresas inspecionadas foi relevante no estudo, sendo que a maioria era do setor privado, com vínculos empregatícios formais, havendo, porém, registro de inspeções em empresas filantrópicas, áreas rurais com trabalhadores informais e autônomos. O princípio da universalidade e equidade do SUS, em que a Visat está pautada, ainda vem sendo um desafio para a Visat. As ações de vigilância realizadas independentemente do local de trabalho, da forma de inserção no mercado de trabalho, do vínculo empregatício e situação de emprego - princípio da universalidade e contemplando todos os trabalhadores, prioritariamente os mais vulneráveis como os trabalhadores informais princípio da equidade ${ }^{26}$, ainda permanecem como perspectiva. É possível que a incorporação das ações de Saúde do Trabalhador pela Atenção Básica e na Estratégia da Saúde da Família promova essa ampliação da cobertura.

Os principais ramos de atividade econômica inspecionados pelo Cesat apresentam-se distribuídos de forma estável no período do estudo, apesar da inclusão e ampliação da ação em outros ramos. As inspeções no ramo da indústria química e petroquímica destacaram-se desde o início das ações do Cesat, podendo indicar que esse ramo se apresenta como área de riscos à saúde dos trabalhadores e, por isso, demanda acompanhamento e monitoramento constante, assim como a indústria de calçados e a construção civil. Entretanto, outros fatores não podem ser omitidos como a maior vocalização na sociedade de algumas categorias profissionais e suas representações políticas e sindicais, como petroleiros e petroquímicos, na determinação das ações de vigilância nesses ramos. Ou seja, a presença de sindicato com forte atuação nas instituições de estado é, sem dúvida, determinante para a ocorrência de ações nas empresas onde estão seus representados. A ação dos sindicatos no MP seguramente está na origem de muitas demandas deles ao Cesat.

Nobre et al. ${ }^{14}$ referem a importância de um diálogo para a discussão das medidas de controle recomendadas nos documentos entre a empresa e os técnicos da Visat. Nesse momento, a empresa pode propor alternativas, as quais devem ser avaliadas conjuntamente, podendo ou não ser acatadas pelos técnicos que realizaram a inspeção. Esses autores referem ainda que algumas empresas oferecem resistência e não acatam os pareceres e recomendações emitidas, dificultando as adequações das condições de trabalho, influenciando diretamente na segurança e na saúde dos trabalhadores. O tempo empregado para elaboração dos documentos técnicos tem sido determinado pela sua natureza investigativa, através de documentos detalhados, relatando os riscos para a saúde do trabalhador. Descrevem-se constatações e diálogos com prepostos e trabalhadores, trazendo recomendações claras e objetivas com base nas regulamentações legais vigentes, conhecimento científico disponível e boas práticas reconhecidas, indicando as medidas necessárias para serem adotadas e prazos para o cumprimento. Este grau de exigência da ação pode justificar o tempo decorrido entre a inspeção e sua documentação. Outro fator determinante no tempo de finalização do documento é a necessidade de mais inspeções no mesmo ambiente a fim de complementar as informações necessárias, o que pode, em alguns casos, gerar um lapso de tempo entre a ação demandada, executada e finalizada.

A redução do quadro de pessoal competente para compor a equipe de inspeção do Cesat é um aspecto que não pode ser omitido ao se discutir a agilidade nos processos e sua conclusão. Além da necessidade da realização de concurso, a inserção de profissionais nas ações de ambientes de trabalho requer maior tempo de capacitação, sendo mais difícil a formação de quadros, com autonomia e habilidades requeridas para essas ações. O trabalho de um técnico em vigilância de ambientes de trabalho implica, sobretudo, a capacidade de lidar com difíceis aspectos da relação política da ação dentro dos ambientes de trabalho repletos de contradições e interesses divergentes entre trabalhadores e empregadores. 


\section{Considerações finais}

O Cesat vem estruturando as ações de Visat no estado, particularmente, através do desenvolvimento de ações de vigilância em ambientes e processos de trabalho, apresentando características que permitem classificá-las como sendo crescentemente de caráter processual, interdisciplinar e interinstitucional, com o envolvimento dos trabalhadores como informante durante as inspeções.

A resolutividade das inspeções foi evidenciada pela análise dos documentos referentes à verificação do cumprimento de recomendações, os quais demonstraram o cumprimento total ou parcial das recomendações feitas anteriormente. Esse tipo de ação ocorre em sua grande maioria em parceria com o MP, em especial nos desdobramentos, devendo ser considerado o poder do órgão na obtenção desses resultados. A emissão de recomendações para adequações nos ambientes e processos de trabalho foi amplamente realizada. Estes achados podem contribuir com o processo de avaliação e consolidação da vigilância em ambientes de trabalho pelo SUS.
Importante ressaltar que nem sempre a efetividade das ações nos ambientes de trabalho poderá ser medida com indicadores de morbimortalidade, especialmente, aqueles utilizados em curto ou médio prazo após as ações, podendo ser constatada, inclusive, pela redução da histórica subnotificação dos agravos relacionados ao trabalho. $\mathrm{O}$ processo de avaliação da efetividade das ações nos ambientes de trabalho requer a construção de indicadores sensíveis a essas peculiaridades, cuja interpretação deve ser crítica e baseada no conjunto de evidências processuais.

O estudo permitiu evidenciar as características das ações de Visat ao longo do período estudado e identificar possíveis tendências, mas indicou o limite de não se obter, para cada caso, a quantidade de inspeção necessária para a finalização do documento técnico.

Para novos estudos em Visat, recomenda-se abordagem qualitativa que permita, a partir dos achados desta investigação, aprofundar a compreensão acerca da vigilância em ambientes de trabalho em suas diferentes dimensões, dentre essas a construção do modelo de Visat na prática cotidiana, a constituição dos sujeitos concretos que edificam esta prática e os desafios da intersetorialidade e do controle social na Visat.

\section{Contribuições de autoria}

Maturino $\mathrm{M}$ fez a revisão de literatura, elaborou a primeira versão do projeto, realizou a coleta e processamento dos dados, participou da análise e interpretação dos dados, elaborou a primeira versão do manuscrito e sua versão final. Fernandes RCP orientou a elaboração do projeto e a revisão da literatura, supervisionou a coleta, instruiu sobre o uso do "software" utilizado na análise, supervisionou o processamento dos dados, participou da análise e interpretação dos dados, colaborou na redação do artigo e realizou a revisão crítica e aprovação da versão final. Rêgo MAV colaborou na redação do artigo e na revisão crítica da versão final.

\section{Agradecimentos}

Agradecemos à equipe do Cesat/Covap, em especial aos gestores, à época da coleta dos dados por viabilizarem e facilitarem o acesso aos documentos técnicos e às informações necessárias para o desenvolvimento da pesquisa.

\section{Referências}

1. Machado JMH. Processo de vigilância em saúde do trabalhador. Cad Saúde Pública. 1997;13(Suppl 2):33-45.

2. Facchini LA. Vigilância em Saúde do Trabalhador: uma aproximação prática. Bol Saúde. 2006;1(20):49-56.

3. Daldon MTB, Lancman S. Vigilância em Saúde do Trabalhador: rumos e incertezas. Rev Bras Saúde Ocup. 2013;38(127):92-106.
4. Fernandes RCP, Rêgo MAV. Construção e consolidação de práticas no Cesat. In: Nobre LCC, Pena PGL, Baptista R, organizadores. A Saúde do Trabalhador na Bahia: história, conquistas e desafios. Salvador: Edufba; Sesab; Cesat; 2011. p. 141-59.

5. Bahia. Portaria $n^{\circ} 2.320$, de 25 de julho de 1995. Estabelece as atribuições do SUS/BA quanto ao desenvolvimento das ações de vigilância da saúde do trabalhador. Diário Oficial do Estado, Salvador, 26 jul 1995. 
6. Fernandes RCP, Nobre LCC. Vigilância de ambientes e processos de trabalho. In: Bahia. Secretaria da Saúde do Estado da Bahia. Superintendência de Vigilância e Proteção da Saúde. Centro de Estudos da Saúde do Trabalhador. Manual de normas e procedimentos técnicos para a Vigilância da Saúde do Trabalhador. Salvador: Cesat; Sesab; 2002. p. 67-84.

7. Nobre LCC, Jacobina A. Bases legais para a Vigilância à Saúde do Trabalhador no SUS. In: Bahia. Secretaria da Saúde do Estado da Bahia. Superintendência de Vigilância e Proteção da Saúde. Centro de Estudos da Saúde do Trabalhador. Manual de normas e procedimentos técnicos para a Vigilância da Saúde do Trabalhador. Salvador: Cesat; Sesab; 2002. p. 29-41.

8. Brasil. Ministério da Saúde. Portaria MS/GM n ${ }^{\circ}$ 3.120 , de $1^{\circ}$ de julho de 1998. Aprova a Instrução Normativa de Vigilância em Saúde do Trabalhador no SUS [Internet]. 1998 [acesso em 2018 jun 13]. Disponível em: http://adcon.rn.gov.br/ACERVO/ cerest/doc/DOC000000000042912.PDF

9. Brasil. Ministério da Saúde. Portaria GM/MS $\mathrm{n}^{\mathrm{o}}$ 1.823, de 23 de agosto de 2012. Institui a Política Nacional de Saúde do Trabalhador e da Trabalhadora [Internet]. 2012 [acesso em 2018 jun 13]. Disponível em: http://conselho.saude. gov.br/web_4cnst/docs/Portaria_1823_12_institui_ politica.pd $\bar{f}$

10. Vasconcellos LCF, Ribeiro FSN. Investigação epidemiológica e intervenção sanitária em saúde do trabalhador: o planejamento segundo bases operacionais. Cad Saúde Pública. 1997;13(2):269-75.

11. Ayres IBSJ, Nobre LCC. Vigilância em Saúde do Trabalhador. In: Bahia. Secretaria da Saúde do Estado da Bahia. Superintendência de Vigilância e Proteção da Saúde. Centro de Estudos da Saúde do Trabalhador. Manual de normas e procedimentos técnicos para a Vigilância da Saúde do Trabalhador. Salvador: Cesat; Sesab. 2002. p. 15-25.

12. Brasil. Ministério da Fazenda. Receita Federal. Classificação Nacional de Atividades Econômicas - CNAE [Internet]. 2014 [acesso em 2018 jun 13]. Disponível em: http://idg.receita.fazenda.gov.br/ orientacao/tributaria/cadastros/cadastro-nacionalde-pessoas-juridicas-cnpj/classificacao-nacionalde-atividades-economicas-2013-cnae

13. Nobre LCC. A política de Saúde do Trabalhador no Brasil e na Bahia. In: Nobre LCC, Pena PGL, Baptista R, organizadores. A Saúde do Trabalhador na Bahia: história, conquistas e desafios. Salvador: Edufba; Sesab; Cesat; 2011. p. 25-92.

14. Nobre LCC, Galvão AMF, Cardim A, Mendes TT. Vigilância em Saúde do Trabalhador no Sistema Único de Saúde: práticas e desafios. In: Nobre LCC, Pena PGL, Baptista R, organizadores. A Saúde do Trabalhador na Bahia: história, conquistas e desafios. Salvador: Edufba; Sesab; Cesat; 2011. p. 277-314.
15. Cardoso EM. Análise conjuntural da Vigilância em Saúde do Trabalhador no estado do Amazonas [tese]. Rio de Janeiro: Escola Nacional de Saúde Pública Sérgio Arouca; 2014.

16. Machado JMH, Santana VS, Campos A, Ferrite S, Peres MC, Galdino A, et al. Situação da Rede Nacional de Atenção Integral em Saúde do Trabalhador (Renast) no Brasil, 2008-2009. Rev Bras Saúde Ocup. 2013;38(128):243-56.

17. Bahia. Secretaria da Saúde do Estado da Bahia. Superintendência de Vigilância e Proteção da Saúde, Diretoria de Vigilância e Atenção à Saúde do Trabalhador. Orientações técnicas para ações de vigilância em ambientes e processos de trabalho. Salvador: Divast; 2012.

18. Minas Gerais. Secretaria de Estado de Saúde de Minas Gerais. Subsecretaria de Vigilância e Proteção à Saúde. Superintendência de Vigilância Epidemiológica, Ambiental e Saúde do Trabalhador. Caderno de organização das práticas de saúde do trabalhador. Belo Horizonte: SES; 2014.

19. Souza NSS, Portinho BG, Barreiros MF. Acidentes de trabalho com óbito registrados em jornais no estado da Bahia. Rev Baiana de Saúde Pública. 2006;30(1):77-89.

20. Feitosa AIR, Fernandes RCP. Acidentes de trabalho com óbito: o jornal impresso como fonte de informação. Rev Bras Saúde Ocup. 2014;39(129):75-85.

21. Jacobina A, Nobre LCC, Conceição PSA. Vigilância de Acidentes de Trabalho graves e com óbito. In: Bahia. Secretaria da Saúde do Estado da Bahia. Superintendência de Vigilância e Proteção da Saúde. Centro de Estudos da Saúde do Trabalhador. Manual de normas e procedimentos técnicos para a Vigilância da Saúde do Trabalhador. Salvador: Cesat; Sesab. 2002. p. 87-115.

22. Vilela RAG, Almeida IM, Mendes RWB. Da vigilância para prevenção de acidentes de trabalho: contribuições da ergonomia da atividade. Ciênc Saúde Coletiva. 2012;17(10):2817-30.

23. Fundação Europeia para a Melhoria das Condições de Vida e de Trabalho. Pesquisas Européias Sobre Condições de Trabalho [Internet]. 2015 [acesso em 2018 jun 16]. Disponível em: https://www. eurofound.europa.eu/surveys/european-workingconditions-surveys

24. Kauppinen T, Toikkanen J. Health and hazard surveillance: needs and perspectives. Scand J Work Environ Health. 1999;25(Suppl 4):61-7.

25. Trivelato GC. Metodologias de reconhecimento e avaliação qualitativa de riscos ocupacionais. São Paulo: Fundacentro; 1998.

26. Brasil. Ministério da Saúde. Gabinete do Ministro. Diretrizes de implantação da Vigilância em Saúde do Trabalhador no SUS [Internet]. 2011 [acesso em 2018 jun 13]. Disponível em: http://www.renastonline.org 
No artigo "A atuação do SUS na vigilância de ambientes de trabalho: a experiência do Centro de Estadual de Referência em Saúde do Trabalhador (Cesat) na Bahia”, com número de DOI: 10.1590/2317-6369000019616, publicado no periódico Revista Brasileira de Saúde Ocupacional, 43:e10, no título, na página 1/13:

\section{Onde se lia:}

A atuação do SUS na vigilância de ambientes de trabalho: a experiência do Centro de Estadual de Referência em Saúde do Trabalhador (Cesat) na Bahia

\section{Leia-se:}

A atuação do SUS na vigilância de ambientes de trabalho: a experiência do Centro Estadual de Referência em Saúde do Trabalhador (Cesat) na Bahia 